\title{
The Complex Effect of External Factors on Asphalt Concrete
}

\author{
Kovalev N.S. \\ Department of Land Cadastre \\ Voronezh State Agricultural University named after Em- \\ peror Peter the Great \\ Voronezh, Russia \\ NSKovalev@mail.ru \\ Gladnev V.V. \\ Department of Land Cadastre \\ Voronezh State Agricultural University named after Em- \\ peror Peter the Great \\ Voronezh, Russia \\ lav-78@mail.ru
}

\author{
Otarova E.N. \\ Department of foreign languages \\ Russian Air Force Military Educational and Scientific Cen- \\ ter "Air Force Academy named after Professor N.E. Zhu- \\ kovsky and Y.A. Gagarin" \\ Voronezh, Russia \\ ekaterina.otarova@mail.ru \\ Sadygov E.A. \\ Department of Land Cadastre \\ Voronezh State Agricultural University named after Em- \\ peror Peter the Great \\ Voronezh, Russia \\ elzas.sadygov@mail.ru
}

\author{
Demidov P.V. \\ Department of Land Cadastre \\ Voronezh State Agricultural University named after Emperor Peter the Great \\ Voronezh, Russia \\ 79204170254@yandex.ru
}

\begin{abstract}
In order to make the nature of asphalt concrete testing close to real conditions of actual operation in road pavements, it seems rational to implement a cycle of tests. During the course of test cycle the consistent accumulation of the results of integrated impact of climatic factors will be performed in the same asphalt concrete samples. A mathematical model of the complex effect of the duration of vibro-vacuum water saturation, ultraviolet irradiation and accelerated freezing-thawing on the compressive resistance of asphalt concrete from slag sand at $+20^{\circ} \mathrm{C}$ has been developed.
\end{abstract}

Keywords - asphalt concrete, slag materials, vibro-vacuum water saturation, ultraviolet irradiation, freezing-thawing complex effect of factors.

\section{INTRODUCTION}

Asphalt concrete is one of the most complex artificial conglomerates, which is mainly reasoned by the peculiarity of its structure, as well as the large dependence of its properties on many external factors. The properties of asphalt concrete materials vary widely, depending on the composition, temperature, type of stress, magnitude of stress and load time. The influence of these factors is ambiguous.

In recent years, a large number of research papers have appeared on the influence of operational and climatic effects on changes in the properties of asphalt concrete. A significant part of these studies is devoted to the modeling of external influences on asphalt concrete in order to predict its operational reliability $[12,13]$.
Existing methods of modeling the operational and climatic effects on asphalt concrete are based on a differential approach to the assessment of the stability of its structure according to the influence of individual factors $[2,10]$. However, such an assessment does not allow taking into account the simultaneous influence of the complex of climatic and compound factors on asphalt concrete, as is the case under actual operating conditions for road pavements.

The existing 9128-2013 on asphalt compounds and asphalt concrete [8] also does not take into account the complex impact of factors. Laboratory methods for the assessment of the quality of asphalt concrete do not reflect the working conditions in coating under varying temperature and humidity conditions. In addition, the characteristics of the properties of asphalt concrete are given by separate independent indicators, and the complex influence of operational and climatic factors on the properties of asphalt concrete is not studied enough. DIN EN 13108-1: 2006-08 [12] also does not take into account the complex impact of external factors.

In addition to dynamic loads, asphalt concrete coatings are affected by such climatic factors as prolonged water saturation, the effects of repeated freezing and thawing, ultraviolet irradiation, aggressive salts and the duration of operation resulting in the destruction of asphalt concrete based on natural stone materials. 


\section{METHODS AND MATERIALS}

The authors of the article proposed and developed a method for the preparation of samples of building materials for strength testing [1]. The essence of the method is in the fact that one and the same samples are affected by a complex of factors, after which the parameters of structural and mechanical properties of the material are determined.

In order to describe the influence of a complex of factors in the study of asphalt concrete, the method of mathematical planning of extreme experiments was applied [5].

This method is widely applied in the selection of optimal compound formulation of materials $[3,6]$.

The combination of complex influence of factors and the mathematical method of planning extreme experiments allows us obtaining mathematical models that connect these effects on the properties of asphalt concrete. Moreover, the sequence of the effects does not affect the obtaining of final result, since each of the impact factors is placed at three levels: from the minimum to the maximum value. Using this method, the studies were conducted on the influence of external factors on asphalt concrete based on natural stone materials [4].

This method differs from multidimensional regression analysis in that the researcher plans his strategy in advance, actively intervenes in the experiment, and does not play the role a passive observer, as described in the research [7].

The mathematical model of the influence of the complex of factors is represented as a polynomial:

$$
\mathrm{Y}=\mathrm{b}_{o}+\sum_{i=1}^{i=n} \mathrm{~b}_{i} \boldsymbol{x}_{i}+\sum_{i=1}^{i=n} \mathrm{~b}_{i j} \boldsymbol{x}_{i} \boldsymbol{x}_{i}+\sum_{i=1}^{i=n} \mathrm{~b}_{i i} \boldsymbol{x}_{i}^{2}
$$

where $\mathrm{b}_{o}-$ free term;

$\mathrm{b}_{i}-$ linear factor;

$\mathrm{b}_{i j}$ - interaction factor;

$\mathrm{b}_{i i}$ - quadratic factor.

Before the planning, the factors are scaled in order to obtain a second-degree polynomial equation for dimensionless quantities xi.

The transition from physical variables $\mathrm{X}^{i}$ to coded $\mathrm{xi}$ is carried out according to the formula

$$
x_{i}=\left(X_{\mathrm{i}}-X_{\mathrm{i}}^{0}\right) / \lambda_{\mathrm{i}}
$$

where $\mathrm{X}_{0}=\left(\mathrm{X}_{i}^{v}+\mathrm{X}_{i}^{n}\right) / 2$ - mid range of $i$ factor;

$\left(X_{\mathrm{i}}^{\mathrm{v}}-X_{\mathrm{i}}^{\mathrm{n}}\right) / 2$ - variation step $i$ factor;

$X_{\mathrm{i}}^{\mathrm{v}}$ and $X_{\mathrm{i}}^{\mathrm{n}}$ - upper and lower levels of variation respectively $i$ factor.

As a result of variable coding, the upper level will correspond to the value " +1 ", zero - "0", lower - "-1".

After the implementation of the experiments, the validity of the coefficients according to the Student's t-test and the model for adequacy according to Fisher's F-test are carried out.
On the territory of Lipetsk region there are no deposits of durable stone materials, and road organizations mainly use imported ones. In addition, the Novolipetsk Metallurgical Complex (NLMC) is located in the region, producing millions of tons of dump and granulated slags, slag- pumice sands and slag sands as by-products every year.

The introduction of these materials in technological process of road construction will reduce the negative impact on the environment, expand the resource base of the industry, improve the quality of road pavements and significantly reduce their cost.

Molten slag rubble, obtained by slow cooling of the fiery liquid blast furnace slag, contains about $10 \%$ of the glass phase. When crushing molten slag stone to crushed stone, a fraction of $0-5 \mathrm{~mm}$ (slag sand) is obtained. This material is characterized by the presence of particles of different strength and rough surface. The presence of glass phase determines the hydraulic activity of slag materials.

A peculiarity of glass phase of slag materials is the sharp difference in the structure and chemical composition of the main mass of glass and the surface layer. It is reasoned by the fact that the surface of glass under atmospheric conditions undergoes changes immediately after its formation, as a result a surface layer appears that differs in chemical composition and physical properties from the rest of the glass mass.

During the processing of molten slag on slag crushed stone, the waste of crushing of molded slag rubble (slag sand) in the amount of $6-8 \%$ of the processed material is formed. For example, the output of slag sand can reach up to 30 thousand tons per year at Novolipetsk metallurgical plant.

The use of slag sand in asphalt compounds is predetermined by the following prerequisites: the granulometric composition of slag sand approaches to the requirements for granulometric composition of sand asphalt concrete compounds of $\mathrm{G}$ type; slag sand grains are sharp with a dense and crusty structure and a rough surface.

This leads to better mutual jamming of particles in asphalt concrete, improving its structural and mechanical properties and increased shear stability of asphalt concrete pavements; having a slag nature, the mineral material actively interacts in compounds with bitumen, translating it into a film structured state.

The chemical composition of slag sand of Novolipetsk Metallurgical Complex is shown in Table 1.

TABLE I. THE CHEMICAL COMPOSITION OF SLAG SAND

\begin{tabular}{|c|c|c|c|c|c|}
\hline \multicolumn{7}{|c|}{ Chemical composition, \% } \\
\hline $\mathrm{SiO}_{2}$ & $\mathrm{CaO}$ & $\mathrm{Al}_{2} \mathrm{O}_{3}$ & $\mathrm{MgO}$ & $\mathrm{FeO}$ & other \\
\hline 37.91 & 42.88 & 11.72 & 5.72 & 0.24 & 1.53 \\
\hline
\end{tabular}

The average density of slag sand is $1.35 \mathrm{~g} / \mathrm{sm} 3$, the true density is $2.82 \mathrm{~g} / \mathrm{sm} 3$, and the emptiness is $52 \%$.

Along with dense and strong grains in the composition of slag sand there are grains with high porosity and brittleness. 
During the concentration the grains of slag sand are crushed and the average strength of the material increases due to the elimination of structural defects. After the concentration with a load of $40 \mathrm{MPa}$, the particle size distribution of the mineral part is optimized and satisfies the requirements of all-Union State Standard 9128-2009 for sand asphalt concrete compound of G type (Fig. 1). According to the figure 1 it is shown that the grains with a size of $1.25 \mathrm{~mm}$ are subjected to the greatest crushability after concentration with a load of $40 \mathrm{MPa}$, and the number of particles smaller than $0.071 \mathrm{~mm}$ is almost doubled. As a result of crushing, the granulometric composition of the mineral part fully meets the requirements of dense compounds.

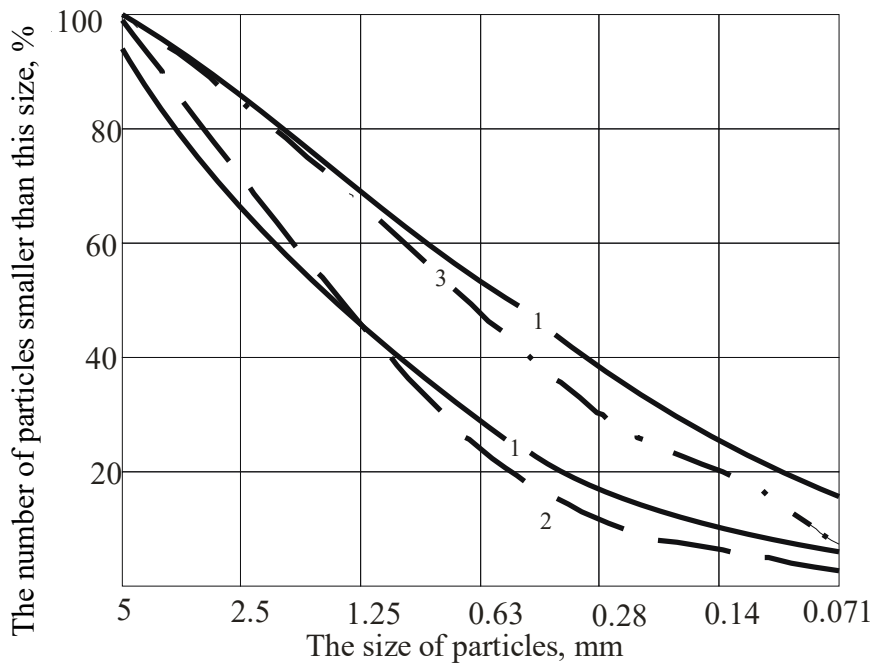

Fig. 1. The changes in the granulometric composition of slag sand in the process of concentration of the asphalt-concrete compound:

1 - the curves of the recommended particle size distribution of $\mathrm{G}$ type according to allUnion State Standard 9128-2013; 2 - initial granulometric composition of slag sand; 3 - granulometric composition of slag sand after concentration of asphalt concrete with a pressure of $40 \mathrm{MPa}$.
The crushing not only ensures the optimization of particle size distribution, but is also accompanied by the formation of fresh surfaces, the energy potential of which is very high. On the basis of the research of the authors it was established that the formation of fresh surfaces in the absence of contaminating impurities leads to chemisorption interaction and an increase in the adhesive bonds between the slag material and bitumen [9].

$x_{1}=\left(\mathrm{X}_{1}-40\right) / 20, x_{2}=\left(\mathrm{X}_{2}-62\right) / 38, x_{3}=\left(\mathrm{X}_{3}-50\right) / 10$.

The following asphalt concrete composition was investigated: slag sand NLMC - $100 \%$, bitumen of BND brand $40 / 60-9 \%$.

In order to study the complex effects on structural and mechanical properties of asphalt concrete from slag materials, we used three factors:

$\mathrm{X} 1$ - the duration of vibro-vacuum water saturation, $\mathrm{h}$;

$\mathrm{X} 2$ - the number of cycles of accelerated freezing and thawing;

$\mathrm{X} 3$ - the duration of ultraviolet radiation, $\mathrm{h}$.

The planning matrix and the planning conditions for the experiment are given in Tables 2 and 3. The rationale for the parameters of the parameters of external influences is given in [9].

The transition from physical to coded variables is carried out according to the formulas:

$$
\mathrm{x} 1=(\mathrm{X} 1-40) / 20, \mathrm{x} 2=(\mathrm{X} 2-62) / 38, \mathrm{x} 3=(\mathrm{X} 3-50) / 10 .
$$

TABLE II. THE CONDITIONS OF THE PLANNING OF EXPERIMENT ON THE INVESTIGATION OF STRUCTURAL AND MECHANICAL PROPERTIES OF SLAG SAND ASPHALT CONCRETE DEPENDING ON THE DURATION OF VIBRO-VACUUM WATER SATURATION, ULTRAVIOLET IRRADIATION AND THE AMOUNT OF ACCELERATED FREEZINGTHAWING CYCLES

\begin{tabular}{|c|c|c|c|c|c|c|}
\hline \multirow[b]{2}{*}{ Conditions } & \multicolumn{3}{|c|}{ Physical value of variables } & \multicolumn{3}{|c|}{ Coded value } \\
\hline & $\begin{array}{l}X^{1} \text { - the duration of vibro-vac- } \\
\text { uum water saturation, } h\end{array}$ & $\begin{array}{c}X^{2}-\text { the amount of accelerated } \\
\text { freezing-thawing cycles }\end{array}$ & $\begin{array}{c}X_{3}-\text { the duration of } \\
\text { ultraviolet irradiation, } \\
h\end{array}$ & $x_{1}$ & $x_{2}$ & $x_{3}$ \\
\hline Upper level $\mathrm{X}_{i}{ }^{v}$ & 60 & 100 & 60 & +1 & +1 & +1 \\
\hline Lower level $\mathrm{X}_{i}{ }^{n}$ & 20 & 24 & 40 & -1 & -1 & -1 \\
\hline Main level $\mathrm{X}_{i}^{0}$ & 40 & 62 & 50 & 0 & 0 & 0 \\
\hline Variation step $\lambda_{i}$ & 20 & 38 & 10 & - & - & - \\
\hline
\end{tabular}


TABLE III. Three-level plan for the second order experiments in the number of following factors: $\mathrm{k}=3\left(\mathrm{~N}=\mathrm{N}_{1}+\mathrm{N} \alpha+\mathrm{N}_{0}\right)$

\begin{tabular}{|c|c|c|c|c|c|c|c|c|c|c|}
\hline \multicolumn{2}{|c|}{ Experiment № } & \multicolumn{3}{|c|}{ Planning matrix $\left(x_{i}\right)$} & \multicolumn{3}{|c|}{ Interaction $\left(x_{i} x_{j}\right)$} & \multicolumn{3}{|c|}{ Square of variables $\left(x_{i}^{2}\right)$} \\
\hline \multirow{8}{*}{$\mathrm{N}_{1}$} & 1 & + & + & + & + & + & + & + & + & + \\
\hline & \multirow{7}{*}{$\begin{array}{r}2 \\
3 \\
4 \\
5 \\
6 \\
7 \\
7 \\
8 \\
\end{array}$} & - & + & + & - & - & + & + & + & + \\
\hline & & + & - & + & - & + & - & + & + & + \\
\hline & & - & - & + & + & - & - & + & + & + \\
\hline & & + & + & - & + & - & - & + & + & + \\
\hline & & - & + & - & - & + & - & + & + & + \\
\hline & & + & - & - & - & - & + & + & + & + \\
\hline & & - & - & - & + & + & + & + & + & + \\
\hline \multirow{6}{*}{$\mathrm{N} \alpha$} & \multirow{6}{*}{$\begin{array}{r}9 \\
10 \\
11 \\
12 \\
13 \\
14\end{array}$} & + & 0 & 0 & 0 & 0 & 0 & + & 0 & 0 \\
\hline & & - & 0 & 0 & 0 & 0 & 0 & + & 0 & 0 \\
\hline & & 0 & + & 0 & 0 & 0 & 0 & 0 & + & 0 \\
\hline & & 0 & - & 0 & 0 & 0 & 0 & 0 & + & 0 \\
\hline & & 0 & 0 & + & 0 & 0 & 0 & 0 & 0 & + \\
\hline & & 0 & 0 & - & 0 & 0 & 0 & 0 & 0 & + \\
\hline \multirow{3}{*}{$\mathrm{N}_{0}$} & 15 & 0 & 0 & 0 & 0 & 0 & 0 & 0 & 0 & 0 \\
\hline & \multirow{2}{*}{$\begin{array}{l}16 \\
17\end{array}$} & 0 & 0 & 0 & 0 & 0 & 0 & 0 & 0 & 0 \\
\hline & & 0 & 0 & 0 & 0 & 0 & 0 & 0 & 0 & 0 \\
\hline
\end{tabular}

\section{RESULTS}

As a result of the implementation of the experiments and calculation of the planning matrix, a mathematical model was obtained for changing the compressive resistance of asphalt concrete at a temperature of $20{ }^{\circ} \mathrm{C}$, depending on the factors listed above (the coefficients are significant by the Student's tcriterion and the model is adequate by Fisher's f-criterion).

$$
\begin{aligned}
& \mathrm{R}_{C}=3,29+0,3 x_{1}+0,21 x_{1} x_{2}+0,4 x_{1} x_{3}-0,11 x_{2} x_{3} \\
& -0,02 x_{1}^{2}+0,42 x_{2}^{2}+0,55 x_{3}^{2}, \mathrm{MPa} .
\end{aligned}
$$

The analysis of the mathematical model made it possible to determine the influence of the exploited climatic factors on the ultimate compressive strength: among the coefficients of variables of the first degree, only the coefficient of vibrational vacuum saturation (x1), which increases the compressive strength is significant;

the coefficients of the paired variables $\mathrm{x} 1 \times 2$ and $\times 1 \times 3$ also lead to an increase, i.e. the phenomenon of synergism of the combined effect of vibrating vacuum water saturation is observed - the number of cycles of accelerated freezing-thawing and vibrating vacuum water saturation - ultraviolet irradiation, and the combined effect of freezing -thawing and ultraviolet irradiation leads to a decrease in compressive resistance;

The coefficients for square of variables have an unambiguous effect on the compressive resistance: the vibrowater saturation slightly reduces, and the effects of accelerated freezing-thawing and ultraviolet irradiation significantly increase the compressive resistance in boundary zones. Positive values at quadratic terms $\times 12$ and $\times 32$ indicate the presence of a minimum strength limit under compression at a temperature of $20^{\circ} \mathrm{C}$.

The diagrams are created according to the obtained mathematical model (fig. 2).

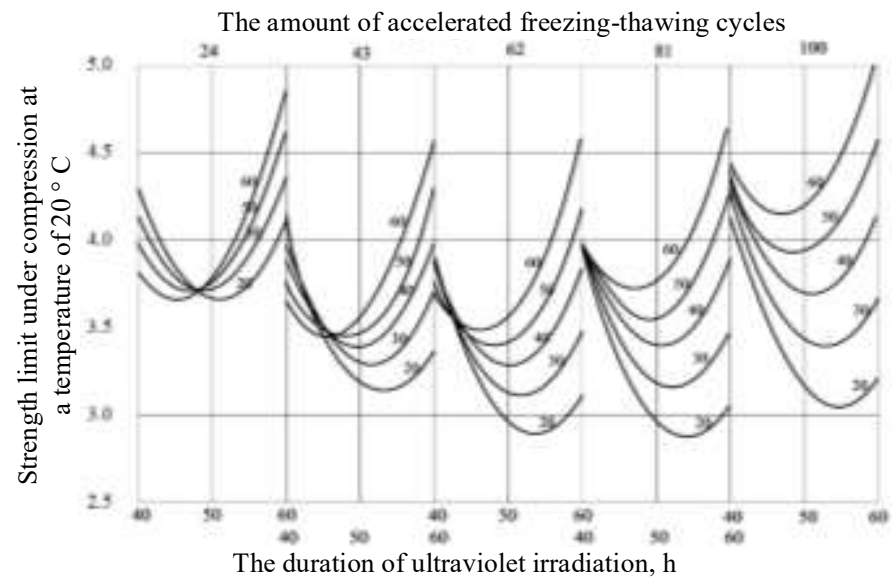

Fig. 1. The complex effect of the duration of vibrating water saturation, ultraviolet irradiation and accelerated freezing-thawing on the compressive resistance of asphalt concrete at a temperature of $+20^{\circ} \mathrm{C}$. The numbers on the curves - the duration of the vibratory water saturation, $\mathrm{h}$

With a minimum number of hours of ultraviolet irradiation and the number of cycles of accelerated freezing-thawing to 62 , the duration of vibratory vacuum water saturation reduces the compressive resistance; and at 100 cycles of accelerated freezing-thawing, the compressive resistance begins to increase with increasing duration of vibratory vacuum saturation.

With the increase in the duration of ultraviolet radiation and the number of cycles of accelerated freezing-thawing, vibrovacuum water saturation leads to a significant increase in compressive resistance, and the longer the freezing-thawing cycles and the duration of ultraviolet irradiation, the greater the increase in strength.

As it can be seen from Figure 2, when exposed to freezingthawing and ultraviolet irradiation, the minimum values of compressive resistance are observed. 
Asphalt concrete on slag materials has specific properties that are not inherent in asphalt concrete on natural stone materials. Slag materials are characterized by hydraulic binding properties, porous structure; their particle size distribution in the process of technological operations (drying, mixing with bitumen, packing and concentration) is optimized. As a result, the processes of structure formation in asphalt concrete of this type occur for a long time after the installation of coatings. Figures 3-5 show images obtained using scanning electron microscopy. The presence of a hydraulically active mineral component leads to the formation of a coagulationcondensation structure strengthened by crystallization joints at the sites of contact of slag grains (Fig. 3).

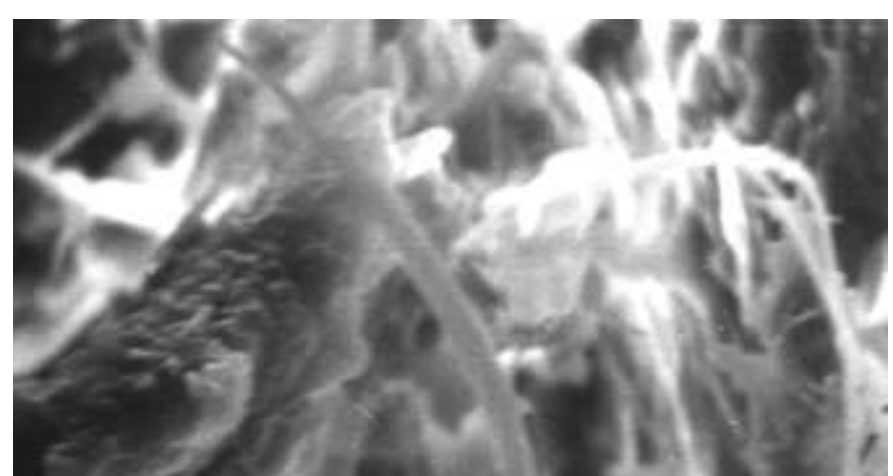

Fig. 3 The emergence of coagulation-condensation structure in the asphaltconcrete compound as a result of the effects of prolonged water saturation and alternating temperatures. Scale 1:1

The modification of the surface of slag grains leads to an increase in the role of van der Waals forces due to an increase in the contact surface between the bitumen and mineral material, since the surface of the new formations is measured by values of the order of 100-300 $\mathrm{m} 2 / \mathrm{g}$. The main influence of surface modification, in our opinion, lies in the fact that crystalline hydrates reinforce bitumen both on the surface of slag material and the bitumen that diffused into the pores. This leads to increased diffuse adhesion between the bitumen and the mineral material. This process is enhanced by prolonged water saturation and exposure to freeze-thaw temperatures (Fig. 4, 5).
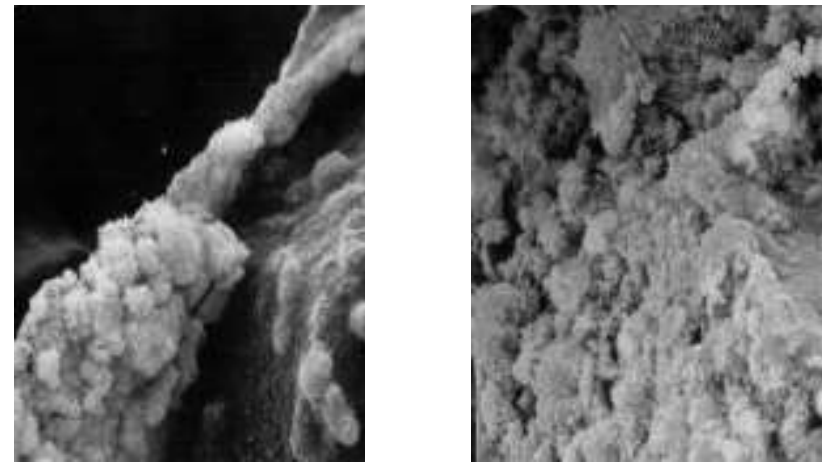

Fig.4 The modification of the surface of slag material after 50 cycles of freezing-thawing. The bitumen is extracted.Scale $-1: 3$

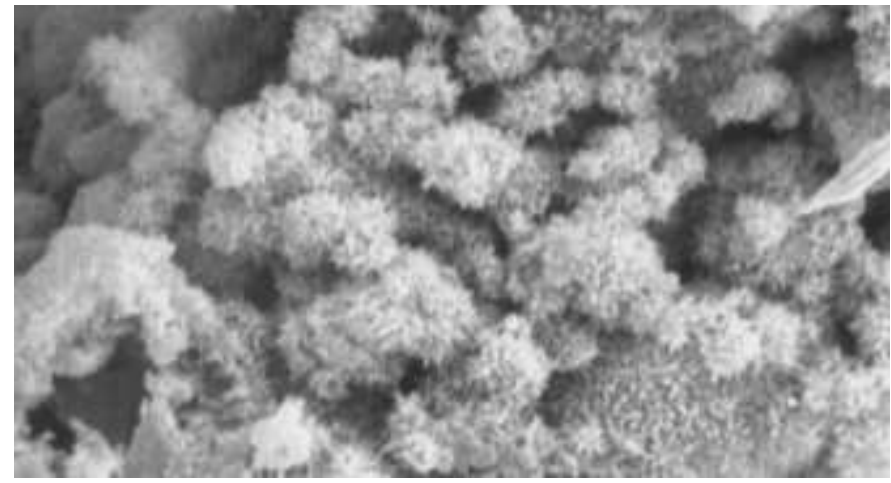

Fig.5 The modification of the surface of slag material after 90 days of water saturation. The bitumen is extracted.Scale $-1: 1$

In general, the interaction of slag materials with bitum allows realizing physical, mechanical, chemical electrostatic and diffusion processes. As a result, the adhesion bomds at the boundary of bitumen - mineral material become durable and more resistant to environmental influences both at the time of consolidation and over time [9].

In the above mentioned studies, the main advantage of asphalt concrete from slag materials is shown in comparison with the traditionally used natural materials, when the complex effect of temperature and humidity changes does not lead to destruction, but, on the contrary, to a significant intensification of the system.

\section{CONCLUSION}

1. The authors proposed and tested the method, the essence of which is that the same sample of asphalt-concrete made of slag materials is influenced by a combination of factors, after which the parameters of the structural-mechanical properties of the material are determined.

2. The complex effect of the duration of vibrating vacuum water saturation, ultraviolet irradiation and accelerated freezing-thawing on the compressive resistance of asphalt concrete at a temperature of $+20^{\circ} \mathrm{C}$ was investigated.

3. A mathematical model has been developed of the complex influence of factors on the compressive resistance limits of asphalt concrete from slag sand at a temperature of 20 ${ }^{\circ} \mathrm{C}$.

\section{References}

[1] B.F. Sokolov, S.I. Samodurov, N.S. Kovalev, Method B.F. Sokolov preparation of building materials for testing the strength, (THE USSR). 2564809; declared 01/04/1978; publ. 05/30/1979. Bul. № 20.

[2] A.S. Tyagov, "Analysis of foreign test methods for asphalt concrete of the upper layers of the pavement", Bulletin of the Rostov State Construction University, Vol. 2, No. 20, pp. 208-214, 2015.

[3] B.A. Bondarev, Yu.V. Stefan, M.A. Goncharova, G.E. Stefan, Asphalt concrete slag aggregates, Lipetsk: LSTU, 2005.

[4] B.F. Sokolov, S.M. Maslov, Simulation of climatic impacts on asphalt concrete, Voronezh: VSU Publishing House, 1987.

[5] V.V. Nalimov, N.A. Chernova, Statistical methods for planning extreme experiments, M .: Science, 1965.

[6] V.I. Bratchun, Yu.V. Gritsuk, V.L. Bespalov, M.K. Pakter, A.V. Gubar, "Asphalt and slag concrete on anionic bitumen emulsions", Science and technology in the road sector, No. 4, pp. 22-26, 2014. 
[7] V.T. Erofeev, M.A. Likomaskina, "Evaluation of the durability of asphalt concrete when tested under climatic conditions with variable humidity, ultraviolet radiation and aggressive sea water”, Vestnik MGSU. № 6, pp. 63-79, 2016.

[8] All-Union State Standard 9128-2013. Compounds of asphalt concrete, polymersphalt concrete, asphalt concrete, polymer asphalt concrete for highways and airfields. Technical conditions, Enter 2014-14-11, Moscow: Standardinform, 2014

[9] N.S. Kovalev, Scientific and practical principles of frost resistance and cracking of asphalt concrete coatings from slag materials: monograph. Voronezh: Voronezh State Agrarian University, 2012.

[10] E.V. Kotlyarsky, "Frost resistance of asphalt concrete", Construction materials, No. 5, pp. 81-84, 2011.
[11] DIN EN 13108-1:2006-08 Asphaltmischgut - Mischgutanforderungen Teil 1: Asphaltcocncrete. German version EN 13108-1:2006: Bituminous mixtures Material specifications. Part 1: Asphalt Concrete.

[12] I. Leonovich, I. Melnikova, V. Puodžiukas, "Estimation of the cracking probability in road structures by modeling of external influences", The Baltic Journal of Road and Bridge Engineering, Vol. 8, №4, pp. 240-249, 2013.

[13] I. Leonovich, I. Melnikova, "Influence of temperature on the formation of damages in asphalt concrete pavements under climatic conditions of the republic of belarus", The Baltic Journal of Road and Bridge Engineering. Vol. 7, №1, pp. 42-47, 2012 . 